\title{
IMPACTOS DA ADOÇÃO DE ATIVIDADES DE RESPONSABILIDADE SOCIAL CORPORATIVA NA ESTRUTURA ORGANIZACIONAL: ESTUDO DAS MULTINACIONAIS ALEMÃS NO BRASIL
}

\section{RESUMO}

Este estudo parte das seguintes questões: quais são os impactos da adoção de atividades de Responsabilidade Social Corporativa - RSC na estrutura organizacional das empresas, bem como o processo de tomada de decisão no contexto internacional, em especial as empresas brasileiras com capital alemão? Esse levantamento foi realizado com 76 empresas alemãs, da indústria de transformação, que atuam no Brasil, portanto, o presente estudo consiste numa pesquisa descritiva de natureza teórica-empírica, com abordagem quali-quantitativo de cunho descritivo, pois a motivação do estudo foi a de caracterizar os impactos da adoção das práticas de RSC na estrutura organizacional das empresas. No entanto, utiliza-se ferramentas de coleta e análise de dados quantitativas de modo a mapear o maior número possível de empresas para o estudo, garantindo a padronização das respostas e facilitando a compreensão do processo de inserção da RSC no Brasil. Observou-se que na coordenação das atividades de RSC, as empresas pesquisadas encontram-se em um estágio embrionário de inserção da RSC em suas estruturas. Concernente ao sistema de tomada de decisão considera-se as filiais brasileiras de multinacionais alemãs como 'agentes ativas' da gestão de RSC nos seus contextos locais. Destaca-se ainda, o fato da RSC ser relevante nas empresas pesquisadas face ao perfil dos responsáveis pelas atividades/programas de RSC e suas respectivas posições na estrutura organizacional. Dessa forma, a presente pesquisa contribui para a discussão da RSC como parte da estratégia da empresa e não mais como ações pontuais e isoladas utilizadas para ancorar ações de cunho propagandista.

Palavras-chave: Responsabilidade Social Corporativa; Tomada de Decisão; Contexto Internacional; Multinacionais.

\section{IMPACTS OF ADOPTING CORPORATE SOCIAL RESPONSIBILITY ACTIVITIES IN THE ORGANIZATIONAL STRUCTURE: A STUDY OF GERMAN MULTINATIONALS IN BRAZIL}

\section{ABSTRACT}

This study is based on the following questions: what are the impacts of adopting CSR activities in a company organizational structure, as well as the decision making process in an international context, especially in Brazilian companies with German capital? This survey was conducted on 76 German companies, operating in the transformation industry in Brazil. Therefore the research was a descriptive theoretical-empirical study with a qualitative and quantitative approach to characterize the impacts of the adoption of CSR practices in the organizational structure of companies. However, it presents quantitative data collection and analysis tools in order to map the largest possible number of companies for the study, ensuring the standardization of responses and facilitating the understanding of CSR insertion process in Brazil. It was also observed that in the coordination of CSR activities, the companies participating in this study were in an embryonic stage of inserting CSR in their structures. Concerning the system of decision making, the Brazilian subsidiaries of German multinationals are considered as 'active agents' of CSR management in their local context. It is important to mention that CSR is relevant to these companies according to the profile of the CSR activities manager and his or her position in the organizational structure. Therefore, this present study contributes to the discussion of CSR as part of company strategy and not as specific and isolated actions that could be simply used as promotional actions.

Keywords: Corporate Social Responsibility; CSR Decision Making In An International Context; Multinationals. 


\section{IMPACTOS DE LA RESPONSABILIDAD DE LAS ACTIVIDADES DE LA ADOPCIÓN DE LAS EMPRESAS EN SOCIAL ESTRUCTURA ORGANIZACIONAL: ESTUDIO MULTINACIONAL DE ALEMÁN EN BRASIL}

\section{RESUMEN}

Este estudio de las siguientes preguntas: ¿Cuáles son los impactos de las actividades de Responsabilidad Social Empresarial - RSE en la estructura organizativa de las empresas, así como el proceso de toma de decisiones en el contexto internacional, empresas, especialmente brasileñas con capital alemana? Esta encuesta se llevó a cabo con 76 empresas alemanas en la industria manufacturera, que opera en Brasil, por lo tanto, el presente estudio es una investigación descriptiva de enfoque teórico y empírico, cualitativo y cuantitativo con un carácter descriptivo, porque la motivación del estudio fue para caracterizar los impactos de las prácticas de RSE en la estructura organizativa de las empresas. Sin embargo, utiliza herramientas de recolección y análisis de datos cuantitativos con el fin de asignar el mayor número posible de empresas para el estudio, lo que garantiza la estandarización de las respuestas y facilitar la comprensión del proceso de inserción de la RSE en Brasil. Se observó que la coordinación de las actividades de RSE, las empresas encuestadas están en una fase embrionaria de la integración de la RSE en sus estructuras. En cuanto al sistema de toma de decisiones se considera las filiales brasileñas de las multinacionales alemanas como la gestión de la RSE "agentes activos" en sus contextos locales. Tenga en cuenta también el hecho de la RSC sea relevante en las empresas encuestadas perfil de la cara de los responsables de las actividades / programas de RSE y sus respectivas posiciones en la estructura organizativa. Por lo tanto, este estudio contribuye a la discusión de la RSE como parte de la estrategia de la empresa y no como específica y acciones aisladas que se utilizan para anclar la naturaleza propagandista de las acciones.

Palabras-clave: Responsabilidad Social Corporativa; Toma de decisiones; Contexto internacional; Las multinacionales.

\footnotetext{
${ }^{1}$ Doutora em Administração pelo Friedrich-Schiller-Universität Jena, Alemanha. Professora da Universidade Federal de Santa Catarina - UFSC. Brasil. E-mail: ewelzel@hotmail.com

2 Professor emérito da Cátedra de Teoria Geral da Administração e Administração da Produção da Friedrich-SchillerUniversit, Alemanha. Alemanha. E-mail: hauptreinhard@web.de

${ }_{3}^{3}$ Doutora pelo Programa de Pós Graduação em Admiistração da Universidade Nove de Julho - PPGA/UNINOVE. Professora na Universidade Federal de Santa Catarina - UFSC. Brasil. E-mail: cibele.martins@ ufsc.br
} 


\section{INTRODUÇÃO}

A responsabilidade social corporativa (RSC) possui vários significados. Para alguns traduz a ideia de 'responsabilidade ou obrigação legal' (Preston \& Post, 1981); para outros significa um 'comportamento ético empresarial' (Homann, 2004; Suchanek, 2003); para um terceiro grupo, expressa a ideia de 'filantropia' (Porter \& Kramer, 2002); uma outra concepção do termo incorpora a noção de 'legitimidade' das empresas (Davis, 1973; Wartick \& Cochran, 1985); o termo pode ainda ser compreendido como obrigação 'fiduciária' empresarial (Freeman, 1984). Seu antônimo pode ser entendido pelos termos de 'irresponsabilidade social' ou 'inexistência de responsabilidade social' (Zenisek, 1979). No entanto, seus significados e meios de implementação variam de acordo com as demandas e realidade de cada país/sociedade.

De um lado, parte-se do pressuposto que o entendimento de RSC difere entre os países. Para os EUA o tema RSC representa a "responsabilidade pessoal por suas próprias ações e impactos na sociedade" (Holme \& Watts, 2000, p. 8, tradução livre). Para a Holanda o termo significa "o engajamento proativo e inclusão, nos valores essenciais da empresa, de questões relativas ao reconhecimento das diferenças locais e culturais ao se implementar políticas globais"; enquanto que para o Brasil a ênfase é o "engajamento na busca do melhor desenvolvimento econômico para a comunidade, do respeito aos colaboradores e a construção de suas capacidades, da proteção do meio-ambiente e colaborar na criação de condições onde negócios éticos possam prosperar", já nas Filipinas o termo é entendido de maneira curta e geral como a "obrigação empresarial de retribuir e dar retorno à sociedade" (Holme \& Watts, 2000, p. 8, tradução livre).

Por outro lado, acadêmicos e empresas procuram um denominador comum de entendimento do tema RSC no contexto internacional. Com essa intenção o documento do Holme e Watts (2000, p. 8) propõe o entendimento de RSC como "o engajamento contínuo do mundo dos negócios em comportar-se eticamente, contribuir para o desenvolvimento econômico, melhorando tanto a qualidade de vida dos colaboradores e suas famílias, quanto o da comunidade local, bem como da sociedade em geral". Essa é uma definição genérica do conceito de RSC e, portanto, apresenta várias possibilidades de entendimento e concretização do tema, suas atividades centrais, as formas de sua coordenação no espaço organizacional, como por exemplo, no das multinacionais.

As multinacionais figuram no cenário internacional de RSC tanto como vilãs ou, antagonicamente, como exemplos a serem seguidos. Neste segundo caso a explicação deve-se ao fato de que estas organizações estão mais expostas à opinião pública e, portanto, tendem a ter um comportamento de 'boas cidadãs' na comunidade internacional no intuito de diminuir uma possível tensão com os países 'hospedeiros' e acessar mais facilmente os recursos dos quais necessita (Naor, 1982). Para tanto, inúmeras vezes as multinacionais precisam se adaptar às demandas locais, o que invariavelmente significa ajustes em termos de sua estruturação. Nesse sentido, formula-se a questão norteadora do presente estudo: quais são os impactos da adoção de atividades de RSC na estrutura organizacional das empresas, bem como no processo de tomada de decisão acerca da RSC no contexto internacional, em especial as empresas brasileiras com capital alemão? Especificamente, pretende-se investigar as formas de inserção da coordenação das atividades de RSC nas empresas, qualificar o tema em termos de nível organizacional de sua implementação, apontar os departamentos envolvidos na implementação das atividades de RSC, descrever o perfil dos responsáveis, apurar a existência de orçamento específico de RSC, relacionar a adequação às certificações com ao engajamento às práticas de RSC e por fim, proceder a caracterização do sistema de tomada de decisão sobre RSC no contexto internacional.

O artigo está estruturado em seis partes principais. Na primeira, apresentada nessa seção, fez-se uma contextualização das definições de RSC em diversos países. A seguir, apresenta-se os principais modelos explicativos de RSC a partir dos estudos comparativos na esfera internacional e discute-se uma tipologia das atividades centrais de RSC. Complementarmente, discute-se as possibilidades de institucionalização da coordenação das atividades de RSC na estrutura organizacional. Na sequência, descreve-se a metodologia empregada para responder à questão norteadora do estudo supracitado. Por fim, apresentam-se os dados do levantamento empírico realizados junto às empresas brasileiras com capital alemão e faz-se uma análise dos principais resultados.

\section{REFLEXÕES INTRODUTÓRIAS SOBRE OS MODELOS DE RSC E TIPOLOGIA DAS PRINCIPAIS ATIVIDADES DE RSC NA ESFERA INTERNACIONAL}

A concepção do termo responsabilidade social corporativa pertence, na literatura acadêmica, à temática moderna do negócio e a sociedade (Matten, Crane, \& Chapple, 2003; Waddock, 2004), onde discute-se a existência de uma empresa como prerrogativa de permissão concedida pela sociedade e, portanto, precisa ter legitimidade para existir (princípio da legitimidade) (Davis \& Frederick, 1985; Wood, 1991). Garriga e Melé (2004) denominam essa 
abordagem como 'constitucionalismo corporativo', que se fundamenta na ideia de que há uma co-dependência entre empresa e sociedade.

Em termos de modelos explicativos de RSC existem 8 modelos principais. O primeiro deles foi elaborado por Zenisek (1979) que definiu três perspectivas de RSC (ideológica societal e operacional). No mesmo ano, Carroll (1979) definiu um modelo tridimensional sobre as categorias de RSC (econômica, legal, ética e discricionária) e a filosofia de responsividade social (reativa, defensiva, acomodada e proativa).

Em 1991 o autor reelaborou as categorias da RSC tendo por base resultados de pesquisas empíricas, originando assim, o modelo de RSC em forma de pirâmide. Este terceiro modelo é tido até o momento como um modelo explicativo fundamental do tema. Com base nesse modelo piramidal a empresa possui quatro graus com categorias diferentes de responsabilidade social, a saber: (1) responsabilidade econômica - a empresa precisa gerar lucro; (2) responsabilidade legal - a empresa deve obedecer à lei; (3) responsabilidade ética - a empresa deve fazer o que é certo e agir sempre de forma correta e leal; (4) responsabilidade de ação discricionária - a empresa deve contribuir para a melhoria das condições da sociedade em geral, engajando-se em projetos sociais comunitários de cunhos educacional, cultural e esportivo (Matten \& Crane, 2005, p. 167). As duas primeiras categorias são exigidas pela sociedade, o que Homann (2004) denominou de 'responsabilidade de ação' das empresas. O terceiro aspecto é esperado pela sociedade, e o quarto é desejado pela sociedade (Carroll, 1991). A essas duas últimas categorias, Homann (2004, p. 6) denominou de 'ampliação da responsabilidade de ação' das empresas.

Tendo por base o trabalho de Carroll (1979), Wartick e Cochran (1985) apresentaram um quarto modelo, onde definiram os principais desafios de RSC como sendo: a responsabilidade econômica, a responsabilidade pública e a responsividade social. Aqui os autores elaboraram um modelo de performance social corporativa onde as categorias de Carroll foram rebatizadas como princípios de RSC e a filosofia de responsividade social em processos, sendo esses redefinidos da seguinte forma: reativa, defensiva, responsiva e interativa. Por último os autores definiram que há a necessidade de incorporar essas duas categorias em um programa e/ou políticas de gestão social no contexto da empresa.

Partindo do trabalho desses autores Wood (1991) modificou o modelo de performance social corporativa de Wartick e Cochran (1985), remodelando os princípios em três níveis: institucional (legitimidade); organizacional (responsabilidade pública); individual (gerenciamento discricionário). Os processos também foram redefinidos em três temas: avaliação do ambiente onde a empresa atua; gestão dos stakeholders e; gestão social. A grande novidade desse quinto modelo refere-se à concretização da implementação das atividades de RSC, a saber: políticas sociais, programas sociais e impactos sociais.

O sexto modelo conceitual da RSC foi proposto por Enderle e Tavis (1998), onde são definidos três níveis éticos para as dimensões principais de RSC (econômica, social e ambiental). Pereira e Campos Filho (2007, p. 6) resumiram esses três níveis, sendo que no primeiro nível, há "requisitos éticos mínimos", portanto, a maximização do lucro tem prioridade em relação às questões morais e éticas; no segundo nível advoga-se que as organizações, em especial as empresas, "tem compromissos além do objetivo econômico, sendo também o de promover o bem-estar da sociedade através de suas ações socialmente responsáveis" e; o terceiro nível caracteriza-se "pelo idealismo ligado à questões éticas, onde a própria existência da organização tem relação fundamental com as demandas sociais".

Especificamente sobre modelos explicativos da RSC em contextos internacionais, os autores Quazi e O'Brien (2000) desenvolveram o modelo bidimensional. Esse sétimo modelo da RSC apresenta duas dimensões: (1) a amplitude da responsabilidade, entendida dentro de uma perspectiva que pode se estender entre extremos que vão de restrita a ampla; (2) os efeitos de ações de RSC, enquadrados em um extremo como benéfica para a empresa e do outro, causadoras de custos.

A contribuição do modelo bidimensional está no fato de que a responsabilidade empresarial é avaliada a partir da perspectiva de seus custos, podendo ser classificada em quadrantes distintos, a saber: (1) a visão clássica, que corresponde ao grau de responsabilidade econômica do modelo de Carroll (1991) e da posição defendida por Friedman (1988) de que a primeira responsabilidade da empresa é gerar lucro; (2) a visão sócio-econômica é uma composição entre os graus da responsabilidade legal e ética de Carroll (1991), onde entende-se que a empresa deva empreender ações sociais desde que estas tragam benefícios para a empresa, ou seja, agir em 'interesse próprio'; (3) a visão moderna, que contempla a combinação entre motivações éticas e os pressupostos da teoria dos stakeholders, tanto para garantir benefícios de curto e longo prazo; (4) a visão filantrópica, a qual corresponde a responsabilidade de ação discricionária de Carroll (1991).

Ainda em relação aos modelos de RSC Schwartz e Carroll (2003) apresentaram um oitavo tipo que se propõe a solucionar alguns problemas dos modelos anteriores. Primeiramente, ao definir como temas centrais da RSC a questão econômica, legal e ética, os autores quebram a concepção equivocada de que a filantropia possui um lugar de destaque. Esta é uma falha constante nos modelos de RSC, por exemplo, no modelo de Quazi e O’Brien onde a 
filantropia possui um lugar de destaque. Já no modelo de Schwartz e Carroll (2003) a filantropia, por sua vez, pode ser observada em ações pontuais tanto dentro da dimensão ética ou econômica. Em segundo lugar ao representar o modelo em um diagrama os autores eliminam a errônea interpretação de que há uma hierarquia entre os temas centrais da RSC. Finalmente, esse modelo considera as possibilidades de combinações entre os temas centrais da RSC, resultando em sete categorizações das atividades das empresas, portanto, desfaz o modelo do "ou", trazendo consigo a possibilidade do "e". Portanto, observa-se que definir RSC é uma tarefa complexa, ainda mais quando se trata de encontrar um consenso internacional. Um dos caminhos possíveis para o esclarecimento do que trata a RSC pode ser a definição de suas principais atividades.
Para tanto, faz-se necessário retomar o conceito de RSC. Nas palavras da comissão da comunidade européia, a RSC pode ser entendida como um "conceito composto de fundamentos sociais e ambientais, aos quais a empresa adere livremente, visando servir e se relacionar de forma integrada com seus stakeholders" (EU-KOMMISSION, 2001, p. 7, tradução livre). Observa-se, portanto, que o conceito de RSC apresenta um amplo espectro de atividades onde fica claro que a elaboração definitiva de uma lista com todos os temas relacionados à RSC é praticamente impossível. No entanto, estudos foram conduzidos onde o tema central refere-se ao significado e compreensão do tema RSC em diferentes países. A compilação destes estudos acerca da RSC em diferentes contextos culturais, é apresentado no quadro 1 . 
Impactos da Adoção de Atividades de Responsabilidade Social Corporativa na Estrutura Organizacional: Estudo das Multinacionais Alemãs no Brasil

\begin{tabular}{|c|c|c|}
\hline Tema principal & Países & Autores \\
\hline \multirow{3}{*}{ Atitudes dos gestores } & UK/India & Khan/Atkinson (1987) \\
\hline & USA/ South Africa & Orpen (1987) \\
\hline & Australia/Blangadesh & Quazi/O'Brien (2000) \\
\hline \multirow[b]{2}{*}{ Categorias de RSC } & $\begin{array}{l}\text { EUA vs. Inglaterra/ Canadá/Japão/Alemanha/ } \\
\text { Holanda/ França }\end{array}$ & Pinkston/Carroll (1994) \\
\hline & $\begin{array}{l}\text { Inglaterra/ França/ Japão/ Suécia/ Alemanha/ } \\
\text { Suíça/ EUA }\end{array}$ & Pinkston/ Carroll (1996) \\
\hline $\begin{array}{l}\text { Responsividade Social } \\
\text { Corporativa }\end{array}$ & Finlândia/Canadá & Nasi et al. (1997) \\
\hline \multirow{3}{*}{ Reporting } & Austrália/ Singapura/ Hongkong/Malásia & Williams/Pei (1999) \\
\hline & Asia (7 paises) & Chapple et al. (2005) \\
\hline & EU & Perrini (2005) \\
\hline Capital Social & Reino Unido/Alemanha & Spence et al. (2003) \\
\hline Elementos de RSC & Alemanha/ Inglaterra & Schmitt (2005) \\
\hline \multirow[b]{2}{*}{$\begin{array}{l}\text { Elementos críticos e } \\
\text { melhores práticas de RSC } \\
\qquad \text { (Best Practice) }\end{array}$} & $\begin{array}{l}\text { Reino Unido/Alemanha/ França/ Itália/ Espanha/ } \\
\text { Noruega/ Hongkong/ Singapura/ Japão/ Coréia/ } \\
\text { Malásia/ Tailândia }\end{array}$ & Welford (2004) \\
\hline & $\begin{array}{l}\text { EUA/ Canadá/ México/ Reino Unido/ } \\
\text { Alemanha/ França/ Itália/ Espanha/ Noruega/ } \\
\text { Hongkong/Singapura/Japão/ Coréia/ Malásia/ } \\
\text { Tailândia }\end{array}$ & Welford (2005) \\
\hline $\begin{array}{l}\text { Desenvolvimento } \\
\text { comunitários em países } \\
\text { em desenvolvimento }\end{array}$ & Nigéria/Africa do Sul & Eweje (2006) \\
\hline Melhores práticas & \multirow{2}{*}{ América Latina } & Peinado-Vara (2006) \\
\hline Trabalho feminino & & Prieto-Carrón (2006) \\
\hline
\end{tabular}

Quadro 1 - Estudo comparativo sobre RSC em contextos internacionais Fonte: Welzel (2009).

A partir desses estudos, pode-se elaborar uma tipologia das principais atividades legais, econômicas, sociais, éticas e ecológicas. Estes, por sua vez, podem ser enquadrados em quatro principais áreas: (1) melhoria das condições sócio-econômicas; (2) meioambiente e processo produtivo; (3) inclusão de stakeholders externos e melhoria da qualidade de vida da comunidade local; (4) condições trabalhistas. Na figura 1 apresentam-se os temas centrais de RSC de cada área. A análise das atividades originou uma classificação em três níveis diferenciados de atuação da empresa: (1) de longo prazo e voltado ao meio externo; (2) de médio prazo e intercalado entre o meio externo e interno; (3) de curto prazo e voltado ao meio interno (WELZEL, 2009). 


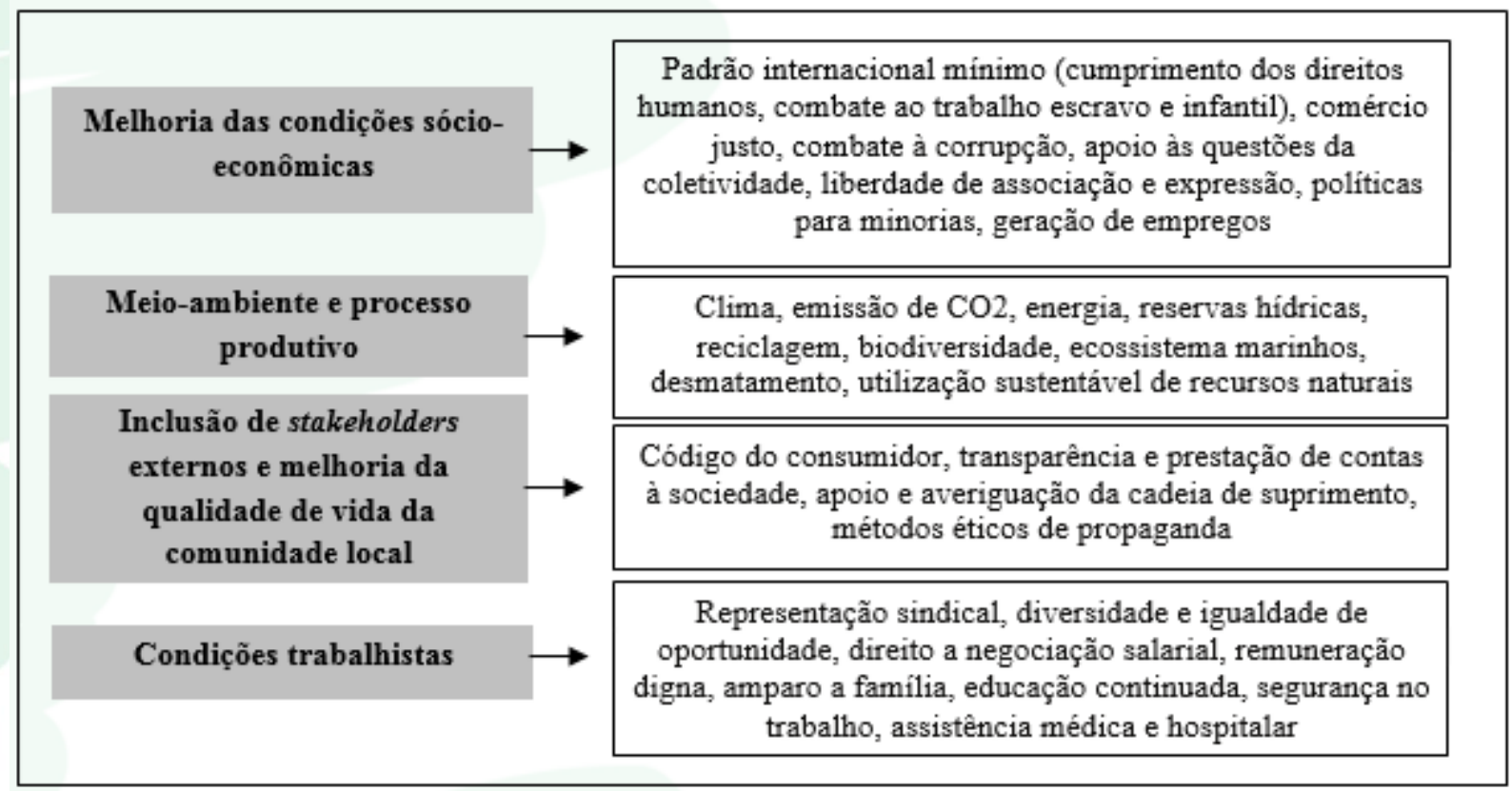

Figura 1: Tipologia das principais atividades de RSC

Fonte: Elaborada pelos autores com base nos estudos do RNE (2006).

No nível de curto prazo, a empresa pode se dedicar à melhoria dos benefícios oferecidos aos seus colaboradores (ambiente de trabalho agradável, previdência privada, seguros de saúde e de vida, auxílio alimentação), garantir condições dignas e seguras de trabalho, oferecer remuneração que possibilite uma vida digna aos colaboradores, bem como programas de educação continuada e desenvolvimento profissional.

Em relação às atividades de médio prazo que estejam ligadas tanto ao meio externo quanto ao meio interno, pode-se salientar o engajamento empresarial em atividades estratégicas, tais como o financiamento de grupos de pesquisas universitárias que podem ser revertidas em tecnologias para a empresa (novos produtos, melhorias do processo produtivo), patrocínio de eventos artísticos, culturais e esportivos que refletem os valores da empresa e, com isso, trazem consigo a atenção dos clientes e, consequentemente, a melhoria da imagem corporativa da empresa. Ainda no segundo nível pode-se classificar as atividades de caráter tático direcionadas para a comunidade local (programas de complementação educacional e incentivo às atividades que aumentem a geração de renda na comunidade), bem como às direcionadas aos clientes internos (combate à discriminação no local de trabalho e na comunidade, melhoria das condições de conciliação entre a vida familiar e o trabalho, como a construção de creches para filhos de funcionários). Além disso, este nível abarca aquelas atividades voltadas aos clientes externos como os métodos e conteúdos de campanhas de promoção e propaganda que sejam éticos, comunicação e transparência do processo de produção, bem como o esclarecimento dos danos potenciais dos produtos da empresa. Complementarmente, incluem-se ainda neste segundo nível as atividades referentes aos fornecedores. Nesse sentido, pode-se averiguar e incentivar à adequação dos padrões de produção que sejam ecologicamente corretos, bem como das condições de trabalho proporcionadas aos funcionários destes fornecedores, quanto ao asseguramento de direitos humanos e do cumprimento da legislação trabalhista, previdenciária e fiscal. Podendo ainda se estender a observância da existência de princípios e políticas relativas à responsabilidade social corporativa por parte dos fornecedores. $\mathrm{O}$ objetivo neste tipo de atividade seria a de fortalecer as relações de negócios e ligação com a comunidade onde a empresa está inserida.

Entretanto, a principal discussão acerca do tema RSC referem-se as atividades de longo prazo e voltadas à melhoria das condições sócio-econômicas fortemente defendidas por organismos supranacionais (RNE, 2006; United Nations, 1999); EU, 2001). Um primeiro grande tema é a defesa dos direitos humanos determinadas pela ONU (ex.: combate ao trabalho escravo e infantil) (United Nations, 1999) e o cumprimento do padrão internacional de trabalho definido pelo 'International Labor Organization' (ILO) (Holme \& Watts, 2000). O segundo grupo de questões diz respeito aos princípios democráticos (direito a representação, igualdade de oportunidade, 
liberdade de expressão e de associação) e da defesa e busca do comércio justo. Além disso, há uma forte discussão e exigência de grupos de pressão e ONGs em relação à criação de políticas de inclusão de minorias (Hopkins, 1997, pp. 599-601; Ostlund, 1977, p. 38). Um terceiro tema importante está relacionado às questões do meio-ambiente e da mudança climática, onde questões delicadas como o respeito à biodiversidade e utilização sustentável dos recursos naturais são consideradas.

No entanto, para abarcar essas atividades de RSC defende-se que a empresa precisa assumir sua responsabilidade na formulação de objetivos, metas e estratégias de negócios (Hansen \& Schrader, 2005; Homann, 2004). Para tanto, faz-se necessária a inserção do tema RSC no cotidiano empresarial. Este é o tema de discutido na próxima seção e objeto de estudo do presente artigo.

\section{COORDENAÇÃO DAS ATIVIDADES DE RSC NA ESTRUTURA ORGANIZACIONAL E TOMADA DE DECISÃO NA ARENA INTERNACIONAL}

A inserção do tema RSC nas organizações pode ser explicada, parcialmente, pelo fato de que há um receio por parte das empresas de que o tema sofra uma regulação e padronização governamental (Loew, Ankele, Braun, \& Clausen, 2004, p. 44). Portanto, é racional que as empresas se antecipem e com isso, evitem uma intervenção direta dos órgãos governamentais. Nesse sentido, observa-se dois movimentos relevantes: a introdução das atividades/programas acerca da RSC no cotidiano empresarial e; o fortalecimento do processo de padronização internacional acerca do tema RSC e sua consequente adoção em forma da certificação pelas empresas.

Relativo ao primeiro movimento, a inserção do tema RSC nas organizações, a primeira fase seria a apropriação do tema RSC no discurso dos dirigentes da empresa como início de sua institucionalização. Tendo por base uma pesquisa qualitativa - realizada com 18 empresas holandesas -, Cramer, Jonker, e van der Heijden (2004, p. 215), constataram que há uma ligação entre os artefatos linguísticos (palavras e definições) utilizados e a condução prática na construção do significado de RSC nas empresas. No entanto, os autores concluíram que o significado é situacional e diretamente influenciado pelas características de quem coordena o assunto. Por conseguinte, segundo os autores, é relevante a verificação da faixa etária, sexo, formação profissional, função e tempo na empresa do responsável pelo tema na empresa.

Numa segunda fase, há a inclusão do tema RSC na estrutura organizacional. Neste caso surge a questão relativa ao nível hierárquico adequado, alocação departamental e número de pessoas envolvidas, bem como a forma de sua inserção. Para diversos autores (Cramer et al., 2004; Habisch, 2006; Naor, 1982; Pinkston \& Carroll, 1994) a temática da RSC pertence ao nível estratégico da tomada de decisão das organizações. Habisch (2006, p. 84, tradução livre) inclusive é enfático ao afirmar que “(...) um conceito estratégico de RSC não é suficiente, porém é uma condição imprescindível para a empresa alcançar um 'bom' engajamento nas questões de RSC“. Portanto, acrescenta-se aqui a necessidade de investigação do envolvimento dos executivos no processo de planejamento e implementação das atividades/programas de RSC. Um estudo pioneiro nesse sentido foi o de Eilbirt e Parket (1973), seguido pelo estudo de Khan e Atkinson (1987) na década seguinte.

Em função do objeto de investigação do presente estudo ser constituído por empresas multinacionais, questiona-se como se dá o sistema de tomada de decisão relativa às atividades de RSC no contexto internacional. Nesse sentido, utilizar-se-á a proposta de Arthaud-Day (2005, p.8) acerca da estratégia internacional de tomada de decisão sobre a RSC. O autor propôs um modelo onde as empresas com atividades ao redor do mundo poderiam optar por quatro abordagens, a saber: transnacional, internacional, global e multinacional (ARTHAUDDAY, 2005, p.18). Essa classificação deriva do modelo de Bartlett e Ghoshal e estão descritas no quadro 2. Cada uma dessas perspectivas pressupõe uma forma de abordar a tensão decisória entre integração global e a adaptação local das estratégias de RSC. 
Impactos da Adoção de Atividades de Responsabilidade Social Corporativa na Estrutura Organizacional: Estudo das Multinacionais Alemãs no Brasil

\begin{tabular}{|c|l|l|}
\hline ABORDAGEM & \multicolumn{1}{|c|}{ DESCRIÇÃO } & \multicolumn{1}{|c|}{ PRESSUPOSTOS } \\
\hline Transnacional & $\begin{array}{l}\text { As práticas e filosofias de RSC são } \\
\text { centralizadas na matriz, mas são adaptadas pelas } \\
\text { filias de acordo com peculiaridades dos países. }\end{array}$ & $\begin{array}{l}\text { Relativismo das práticas de RSC de } \\
\text { acordo com cada país à partir de uma } \\
\text { diretriz centralizada na matriz. }\end{array}$ \\
\hline Internacional & $\begin{array}{l}\text { A matriz exporta para as filiais estrangeiras as } \\
\text { práticas e filosofias de RSC sem modificação. }\end{array}$ & $\begin{array}{l}\text { Know-how da matriz é superior e, } \\
\text { portanto, esta deve decidir o que e } \\
\text { como a RSC deve ser implementado. }\end{array}$ \\
\hline Global & $\begin{array}{l}\text { Existe apenas uma política de práticas e } \\
\text { filosofias de RSC para todas as unidades da } \\
\text { empresa ao redor do mundo. }\end{array}$ & $\begin{array}{l}\text { Generalista e universalismo de práticas } \\
\text { de RSC. }\end{array}$ \\
\hline Multinacional & $\begin{array}{l}\text { Cada país possui uma política de gestão da } \\
\text { RSC. }\end{array}$ & $\begin{array}{l}\text { Diversidade de práticas de RSC, } \\
\text { autonomia das unidades e respeito as } \\
\text { particularidades de cada país. }\end{array}$ \\
\hline
\end{tabular}

Quadro 2 - Descrição das abordagens do sistema de tomada de decisão de RSC no contexto internacional Fonte: adaptado de Arthaud-Day (2005, p.9).

As empresas que se baseiam no sistema multinacional de tomada de decisão possuem um espectro maior de possibilidades de aplicação da RSC, pois suas filiais funcionam como laboratórios de geração de práticas de RSC, tendo em vista, que neste sistema a realidade e demanda de cada país são consideradas. No lado oposto, o sistema global oferece a vantagem de criação de uma identidade das práticas de RSC para a corporação, além de oferecer a possibilidade de comparação destas entre si, já que são implementadas a partir dos mesmos parâmetros. A abordagem transnacional surge como uma alternativa intermediária, entre o universalismo da abordagem global e a especificidade da multinacional, onde a base origina-se da mesma fonte, ou seja, a matriz. Por conseguinte pode-se manter um certo padrão das práticas de RSC. Por fim, o sistema internacional promove, em tese, a elevação dos padrões das práticas de RSC, pois parte do princípio de que as estratégias desenvolvidas na matriz possuem um nível mais elevado de exigência.

Apesar desta classificação esclarecer as possíveis diferenças de abordagens das estratégias de tomada de decisão de RSC praticadas pelas multinacionais, em seu trabalho Arthaud-Day (2005) não fornece comprovação empírica do modelo. A intenção aqui, portanto, é evidenciar qual destes sistemas é utilizado pelas empresas pesquisadas.

$\mathrm{Na}$ direção da institucionalização internacional da RSC, há uma segunda discussão do tema em termos de seu fortalecimento que, inclusive, apresenta semelhanças com o processo de tomada de decisão acima delineado. Nesse sentido, observa-se duas direções distintas: a legitimação das práticas de RSC a partir da perspectiva local e; o processo de padronização internacional e a consequente adoção de certificações internacionais.

$\mathrm{O}$ primeiro caso refere-se ao surgimento de rankings nacionais ao redor do mundo que atribuam às empresas o título de "Good Companies" (Gazdar, 2006, p.54) ou a atribuição de selos - como o da Associação Brasileira dos Fabricantes de Brinquedo ABRINQ, produtos Bio, etc. -, que comprovem o engajamento e a adesão das empresas às causas comunitárias ou de cunho moral e ético elevado, bem como o respeito destas frente os processos ou padrões socioambientalmente responsáveis. Este tipo de adesão, que por consequência produz melhoria em termos de imagem das empresas, tem crescido na última década, porém o efeito deste tipo de prática se restringe ao ambiente local, onde tais 'selos' e premiações tenham significado.

No segundo caso, cresce a busca das empresas por certificações que as projetem e lhes conceda legitimidade internacional. Segundo Loew et al. (2004, p. 46) a iniciativa das organizações certificadoras são fontes importantes na introdução da discussão de RSC na esfera internacional. Isto se deve ao fato de que a busca por um padrão internacional largamente aceito, requer a colaboração e extensos debates de diversos segmentos da sociedade. Em termos específicos, o objetivo deste artigo é identificar se a adequação a certificação internacional resulta em observância e introdução de práticas de RSC nas empresas pesquisadas.

\section{METODOLOGIA}

O presente estudo consiste numa pesquisa descritiva de natureza teórica-empírica. De acordo com Gil (1996), os estudos descritivos visam descrever as características de uma determinada população ou fenômeno, ou ainda, o estabelecimento de relações entre as variáveis. Essa metodologia é adequada, haja vista a necessidade de descrever as formas de inserção da coordenação das atividades de RSC nas empresas, relacionar a adequação às certificações com o 
engajamento às práticas de RSC e proceder a caracterização do sistema de tomada de decisão sobre RSC no contexto internacional.

A população estudada é constituída por empresas brasileiras com capital alemão, portanto multinacionais. A escolha da amostra foi intencional com base em quatro critérios: empresas que tivessem plantas industriais nos dois países, existência de certificação ISO 14001, ramo de atividade e acessibilidade as empresas. $\mathrm{O}$ primeiro critério objetivou eliminar empresas que possuem apenas representações comerciais no Brasil, portanto, a amostra estudada é composta pela indústria. O segundo critério foi escolhido em função do objetivo da pesquisa principal ser motivada pela investigação e comparação entre empresas dos dois países e que já tivessem atividades de RSC. Para tanto, pressupôs-se que a obtenção da certificação ambiental garantiria essa prerrogativa. No entanto, no momento da pesquisa o número de empresas com certificação ISO 14001 no Brasil na população estudada era insuficiente em termos estatísticos, portanto, utilizou-se como terceiro critério o ramo de atividade. Este critério tem o propósito de manter a proporcionalidade na amostra de cada ramo de atividade encontrada na população pesquisada. Por conseguinte há dois grupos de empresas estudadas: grupo de empresas certificadas com a ISO 14001 e o grupo geral de empresas. A acessibilidade foi o quarto critério, pois partiu-se de uma lista de endereços de empresas alemãs no Brasil e havia a necessidade de adesão à pesquisa. Foram contatadas 129 empresas e destas 76 se dispuseram a participar do levantamento. A amostra está descrita na tabela 1

Tabela 1 - Descrição geral da amostra pesquisada

\begin{tabular}{|l|c|c|c|}
\hline \multicolumn{1}{|c|}{ Ramo de atividade } & $\begin{array}{c}\text { Grupo de empresas com } \\
\text { certificação ISO 14001 }\end{array}$ & $\begin{array}{c}\text { Grupo geral de } \\
\text { empresas }\end{array}$ & $\begin{array}{c}\text { Total da } \\
\text { Amostra }\end{array}$ \\
\hline Automobilístico & 11 & 6 & $\mathbf{1 7}$ \\
\hline Químico & 5 & 5 & $\mathbf{1 0}$ \\
\hline Eletro-eletrônico & 5 & 5 & $\mathbf{1 0}$ \\
\hline Metal-mecânico & 5 & 25 & $\mathbf{3 0}$ \\
\hline Ramos diversos & 5 & 4 & $\mathbf{9}$ \\
\hline \multicolumn{1}{|c|}{ Total } & $\mathbf{3 1}$ & $\mathbf{4 5}$ & $\mathbf{7 6}$ \\
\hline
\end{tabular}

Fonte: elaborada pelos autores.

A abordagem do estudo é quali-quantitativo de cunho descritivo, pois a motivação do estudo foi a de caracterizar os impactos da adoção das práticas de RSC na estrutura organizacional das empresas. No entanto, utiliza-se ferramentas de coleta e análise de dados quantitativas de modo a mapear o maior número possível de empresas para o estudo, garantindo a padronização das respostas e facilitando a compreensão do processo de inserção da RSC no Brasil. Os dados primários foram coletados através de entrevistas, tendo como instrumento um questionário estruturado, não disfarçado, respondido pelos indivíduos ligados ao problema da pesquisa, ou seja, responsáveis pelo tema RSC nas empresas. Nos casos em que não havia esse responsável, entrevistou-se o responsável pela empresa. $\mathrm{O}$ contato foi por telefone, devido ao fato de diversas empresas estarem localizadas distantes geograficamente. Para a interpretação de dados foram utilizados métodos estatísticos descritivos com a elaboração de quadros e gráficos. Para tanto, partiu-se da definição de categorias de análise, seu desdobramento em fatores e critérios de análise. Estes itens estão descritos no quadro 3 . O período da coleta de dados primários foi de novembro de 2007 a março de 2008.

$\mathrm{Na}$ coleta de dados secundários foi utilizada pesquisa bibliográfica, que visou selecionar fontes bibliográficas com passagens relevantes para o esclarecimento do tema a ser desenvolvido. Derivada deste levantamento teórico construiu-se proposições centrais do estudo, que serviram de base para a comparação dos resultados do levantamento empírico, portanto, procedeu-se uma pesquisa analíticodescritiva. 
Impactos da Adoção de Atividades de Responsabilidade Social Corporativa na Estrutura Organizacional: Estudo das Multinacionais Alemãs no Brasil

\begin{tabular}{|c|c|c|c|}
\hline $\begin{array}{l}\text { Categorias de } \\
\text { análise }\end{array}$ & Fatores & Critérios de análise & Proposições \\
\hline \multirow{2}{*}{$\begin{array}{c}\text { RSC em } \\
\text { Multinacionais }\end{array}$} & $\begin{array}{l}\text { Adequação a } \\
\text { certificação } \\
\text { internacional }\end{array}$ & Tipo de certificação & $\begin{array}{l}\text { Empresas que possuem certificação tendem a } \\
\text { se dedicar às atividades de RSC. }\end{array}$ \\
\hline & $\begin{array}{l}\text { Sistema de tomada de } \\
\text { decisão relativa às } \\
\text { atividades de RSC }\end{array}$ & $\begin{array}{l}\text { Transnacional } \\
\text { Internacional } \\
\text { Global } \\
\text { Multinacional }\end{array}$ & $\begin{array}{l}\text { Considerando o contexto internacional o atual } \\
\text { sistema de tomada de decisão relativa às } \\
\text { atividades de RSC nas empresas pesquisadas é } \\
\text { o multinacional. }\end{array}$ \\
\hline \multirow{13}{*}{$\begin{array}{l}\text { Coordenação da } \\
\text { RSC na } \\
\text { estrutura } \\
\text { organizacional }\end{array}$} & \multirow{5}{*}{$\begin{array}{l}\text { Perfil dos } \\
\text { responsáveis pelas } \\
\text { atividades de RSC }\end{array}$} & $\begin{array}{l}\text { Formação } \\
\text { profissional }\end{array}$ & \multirow{5}{*}{$\begin{array}{l}\text { O responsável específico pelas atividades de } \\
\text { RSC na empresa é do sexo masculino, possui } \\
\text { experiência de mais de } 2 \text { anos na empresa, } \\
\text { preponderantemente possui formação } \\
\text { acadêmica e ocupa uma posição de direção no } \\
\text { setor em que trabalha. }\end{array}$} \\
\hline & & Idade & \\
\hline & & Sexo & \\
\hline & & Função na empresa & \\
\hline & & Tempo de empresa & \\
\hline & \multirow{6}{*}{ Departamentos } & Número de pessoas & $\begin{array}{l}\text { Empresas, que possuem atividades de RSC, } \\
\text { possuem uma ou mais pessoas responsáveis } \\
\text { pelo desenvolvimento e implementação destas } \\
\text { atividades. }\end{array}$ \\
\hline & & \multirow{2}{*}{ Nível hierárquico } & $\begin{array}{l}\text { O nível hierárquico do responsável pelas } \\
\text { atividades de RSC pertence ao alto escalão da } \\
\text { executivo. }\end{array}$ \\
\hline & & & \multirow{2}{*}{$\begin{array}{l}\text { Caso a(s) pessoa(s) designada(s) para } \\
\text { coordenar as atividades de RSC não pertencer } \\
\text { ao alto escalão do executivo, esta(s) estará } \\
\text { diretamente subordinadas ao corpo diretivo da } \\
\text { empresa. }\end{array}$} \\
\hline & & \multirow{2}{*}{$\begin{array}{l}\text { Envolvimento dos } \\
\text { executivos }\end{array}$} & \\
\hline & & & $\begin{array}{l}\text { O planejamento e implementação das } \\
\text { atividades de RSC cabe ao nível estratégico da } \\
\text { cadeia escalar nas empresas pesquisadas. }\end{array}$ \\
\hline & & \multirow[t]{2}{*}{$\begin{array}{c}\text { Alocação } \\
\text { departamental }\end{array}$} & $\begin{array}{l}\text { A coordenação e gerenciamento do orçamento } \\
\text { das atividades/programas de RSC ficam a } \\
\text { cargo do departamento de marketing. }\end{array}$ \\
\hline & \multirow{2}{*}{$\begin{array}{c}\text { Existência de } \\
\text { orçamento específico } \\
\text { para RSC }\end{array}$} & & \\
\hline & & $\begin{array}{l}\text { Responsabilidade } \\
\text { hierárquica }\end{array}$ & $\begin{array}{l}\text { Existe um orçamento específico para o } \\
\text { desenvolvimento de atividades/programas de } \\
\text { RSC pertence ao alto escalão da executivo. }\end{array}$ \\
\hline
\end{tabular}

Quadro 3 - Relação das categorias, fatores e critérios de análise

Fonte: Elaborado pelos autores.

\section{A RSC NA ESTRUTURA ORGANIZACIONAL E SUA INTERNACIONALIZAÇÃO: ESTUDO DAS EMPRESAS MULTINACIONAIS ALEMÃS NO BRASIL}

\subsection{Inserção da RSC na esfera organizacional}

De acordo com levantamentos anteriores (Cramer et al., 2004; Eilbirt \& Parket, 1973; Naor, 1982) as atividades de RSC ficariam a cargo de executivos de alto escalão. Inclusive Cramer et al.(2004, p. 217) apontam que a inserção do tema neste nível hierárquico é mais fácil, devido à visão de longo prazo dos executivos, característica esta, intrínseca ao tema RSC. Complementarmente a esta afirmação Habisch (2006, p. 39) salienta o fato de que o envolvimento direto dos executivos é a garantia de que as atividades de RSC serão implementadas, pois o autor os considera uma forma de 'guardiões da RSC'.

Considerando a tabela 2 fica evidente que a RSC é tratada como um tema estratégico pelas empresas pesquisadas, haja vista que em $83,5 \%$ delas a presidência/diretoria se envolve diretamente no planejamento e implementação das atividades/programas de RSC e para $73,5 \%$ das empresas essa é uma incumbência da média gerência. 
Impactos da Adoção de Atividades de Responsabilidade Social Corporativa na Estrutura Organizacional: Estudo das Multinacionais Alemãs no Brasil

Tabela 2 - Envolvimento no planejamento e implementação das práticas de RSC

\begin{tabular}{|l|c|c|c|c|}
\cline { 2 - 5 } \multicolumn{1}{c|}{} & $\begin{array}{c}\text { Envolvimento no planejamento } \\
\text { e implementação das } \\
\text { atividades/programas de RSC }\end{array}$ & $\begin{array}{c}\text { Atribuição da } \\
\text { responsabilidade de um } \\
\text { orçamento para } \\
\text { atividades/programas de RSC }\end{array}$ \\
\cline { 2 - 5 } & $\begin{array}{c}\text { Dados } \\
\text { absolutos }\end{array}$ & $\begin{array}{c}\text { Porcentagem } \\
\text { das respostas }\end{array}$ & $\begin{array}{c}\text { Dados } \\
\text { absolutos }\end{array}$ & $\begin{array}{c}\text { Porcentagem } \\
\text { das respostas }\end{array}$ \\
\hline Presidência/Diretoria & 50 & $\mathbf{8 3 , 5}$ & 20 & $\mathbf{3 3 , 5}$ \\
\hline Média Gerência & 44 & $\mathbf{7 3 , 5}$ & - & - \\
\hline Departamentos de Gestão de Pessoas & 37 & $\mathbf{6 1 , 5}$ & 9 & $\mathbf{1 5}$ \\
\hline Responsável específico para RSC & 23 & $\mathbf{3 8 , 5}$ & 4 & 6,5 \\
\hline Comitê com diversos departamentos & 21 & 35 & 2 & 3,5 \\
\hline Matriz na Alemanha & 19 & 31,5 & - & - \\
\hline Conselho da empresa & 17 & 28,5 & - & - \\
\hline Comissão de empregados(as) & 9 & 15 & - & - \\
\hline Assessoria/consultoria externa & 9 & 15 & - & - \\
\hline Setores/departamentos de RSC & 8 & 13,5 & 2 & 3,5 \\
\hline Setores/departamentos de Marketing & 7 & 11,5 & 2 & 3,5 \\
\hline Setores/departamentos de Controladoria & 7 & 11,5 & 5 & 8,5 \\
\hline Setores/departamentos de Produção & 6 & 10 & - & - \\
\hline Stakeholders externos & 6 & 10 & - & - \\
\hline Todos os colaboradores & 4 & 6,5 & - & - \\
\hline $\begin{array}{l}\text { Setores/departamentos de Comunicação } \\
\text { e/ou Relações Públicas }\end{array}$ & 3 & 5 & 3 & 5 \\
\hline Outros & 1 & 1,7 & 2 & 3,5 \\
\hline $\begin{array}{l}\text { Não tem orçamento específico para as } \\
\text { atividades de RSC }\end{array}$ & - & - & 27 & $\mathbf{4 5}$ \\
\hline
\end{tabular}

Fonte: elaborada pelos autores.

Analisando a tabela 2 é possível verificar duas tendências. A primeira refere-se à similaridade da inserção da RSC no espaço organizacional com o surgimento do departamento de Marketing nos anos 70 (Habisch, 2006, p.35), isto é, os dados apontam para a institucionalização da RSC nas empresas pesquisadas. Para 38,5\% das empresas pesquisadas há uma pessoa responsável pelo tema de RSC e para $13,5 \%$ o estabelecimento de um departamento próprio para a RSC já é uma realidade (Tab. 2). Especificamente sobre o tamanho deste departamento, as empresas pesquisadas que o possuam, apontam que em $50 \%$ dos casos há a dedicação de três pessoas e para $26 \%$ das empresas este número chega a seis pessoas.

Nos casos de empresas onde há uma pessoa responsável pelo tema RSC foi adicionalmente averiguado sua subordinação na cadeia escalar. A maioria, $71 \%$ das empresas respondentes, apontaram para uma subordinação direta do responsável pelas atividades/programas de RSC à presidência/diretoria de suas empresas. Em $21 \%$ dos casos o reporte se dá em relação à média gerência. Reforça, portanto, o tratamento estratégico atribuído a coordenação das atividades/programas de RSC.
A segunda tendência observada na tabela acima é o fortalecimento do compartilhamento da responsabilidade acerca da coordenação das atividades/programas de RSC por diversos setores da empresa. Nesse sentido, os dados indicam algumas possibilidades como comitês formados por diversos departamentos da empresa - opção escolhida por $35 \%$ das empresas respondentes -, ou através do conselho administrativo/consultivo da empresa, alternativa apontada por $28,5 \%$ das respondentes. Uma outra possibilidade é a atribuição para a comissão de empregados, que não necessariamente representam departamentos diferentes. Para $15 \%$ dos respondentes esta foi a opção escolhida.

Num primeiro momento, essas duas tendências podem parecer contraditórias. No entanto, também podem ser entendidas como complementares. Nesse sentido, os comitês, comissões ou conselhos decidem acerca das diretrizes, linhas gerais, objetivos e prioridades de atividades/programas. Estes por sua vez, serão planejados, organizados, coordenados e implementados pela pessoa ou departamento responsável pela RSC. Pode-se perceber na tabela 2 que existe ainda uma terceira opção de coordenação da 
RSC através de um consultor externo, opção apontada por $15 \%$ das empresas respondentes. Esta seria uma 'forma intermediária' de inserção do tema na agenda estratégica da empresa.

Por último, nota-se na tabela 2 que há o envolvimento direto de stakeholders externos no processo de planejamento e implementação da RSC. Dentre os $10 \%$ dos respondentes que indicaram esta resposta, foi questionado a quem se referiam. De acordo com as respostas espontâneas foram mencionados representantes da comunidade local. A comunicação da organização com seus stakeholders é uma etapa fundamental para o planejamento e implementação das práticas de RSC (Habisch, 2006, p.85). A partir disso, pressupõe-se que a gestão da RSC seria alocada - em casos onde ainda não exista um setor responsável especificamente pela RSC -, nos departamentos responsáveis pelas atividades de marketing, comunicação institucional e/ou relações públicas (Cramer et al., 2004, p. 216; Eilbirt \& Parket, 1973, p. 49).

Em termos de alocação departamental, nos casos das empresas pesquisadas em que não há especificamente um departamento para RSC, mas sim um responsável para este tema, foi levantado a qual departamento este se reportava. Para $61,5 \%$ dos respondentes o tema é de responsabilidade da área de gestão de pessoas. Outros setores como marketing, controladoria, operações, relações públicas receberam baixas taxas de respostas entre $11,5 \%$ e $5 \%$ (vide tab. 2). Quando apontada a alternativa 'outros', foi espontaneamente indicado o setor de 'segurança e qualidade'. A explicação disso pode ter origem no fato da atual tendência de associar a RSC às formas de normalização e certificações do tema, como ISO 14001, SA 8000 e AA1000. Todos esses são sistemas de gestão e, portanto, podem ter 'migrado' para o setor de qualidade, haja visto que este departamento é responsável pelas outras certificações e sistemas de gestão das empresas.

No intuito de compreender ainda mais a inserção da coordenação de RSC nas empresas pesquisadas, passa-se a descrever o perfil dos responsáveis pelas suas atividades e programas. Relativo a faixa etária, $62 \%$ dos responsáveis específicos pela RSC nas empresas pesquisadas possuem mais do 36 anos, porém não há uma idade predominante. A maioria, $56 \%$, são homens e em relação a formação profissional, 89\% dos respondentes tem formação acadêmica. Neste caso, 34\% são formados em administração, $15 \%$ em ciências da comunicação e $11 \%$ em engenharia.

Concernente a função na empresa, $43 \%$ dos responsáveis pelas atividades/programas de RSC estão alocados ao departamento de gestão de pessoas, $42 \%$ ocupam funções de média gerência (gerentes ou coordenadores de suas áreas) e $15 \%$ ocupam funções na presidência/diretoria. $O$ tempo de trabalho na empresa é de mais de 10 anos em $38 \%$ dos casos e entre 3 e 10 anos para $35 \%$ dos casos.

Os resultados do perfil dos responsáveis pela RSC no presente levantamento estão em consonância com estudos antes publicados. Orpen (1987, p. 90) num estudo comparativo entre EUA e a África do Sul, identificou que os responsáveis pela RSC trabalhavam, em sua maioria, há mais de 15 anos nas suas empresas, possuíam graduação (72\% nos EUA e $61 \%$ na África do Sul) e pertenciam à faixa etária em torno de 47 anos para executivos de ambos os países. No levantamento de Eilbirt e Parket (1973, p. 49) $61 \%$ possuíam graduação, $81 \%$ tinham idade acima de 41 anos. Portanto, em linhas gerais, trata-se de um profissional maduro, com experiência e tempo de empresa.

Em termos de alocação departamental Orpen (1987, p. 90) indica em sua pesquisa que 68\% dos responsáveis pela RSC nos EUA ocupavam a posição de CEO, já na África do Sul $72 \%$ ocupavam essa função. No estudo de Eilbirt e Parket (1973, p. 47), $75 \%$ ocupavam esta posição. Portanto, em relação à posição hierárquica, os resultados do presente estudo corroboram parcialmente os dados anteriormente levantados, já que os dados apontam para uma tendência da atribuição da responsabilidade acerca da RSC para o nível gerencial médio. Contudo, nestes casos este responsável responde diretamente, em $71 \%$ dos casos, ao presidente/diretoria das empresas pesquisadas. Isto posto, observa-se a tendência de atribuir a responsabilidade da RSC para pessoas em cargos de direção.

Com a finalidade de verificar a autonomia na gestão da RSC nas empresas questionou-se sobre a existência de um orçamento específico para a realização de suas práticas. Nesse sentido, verifica-se a inexistência deste instrumento em $45 \%$ das empresas respondentes. Um primeiro esclarecimento para esta carência de orçamento específico para o tema deve-se ao fato de as práticas de RSC, como discutido na seção 2, abarcam diversos temas, atividades e programas, que, por conseguinte requerem o conhecimento e envolvimento de diversos setores da empresa. Dessa forma, a saída mais racional seria a alocação distribuída entre os departamentos envolvidos na implementação destes eventos. Outra explicação seria a aprovação segundo as necessidades emergentes, ou seja, quando um projeto de RSC fosse apresentado e aprovado, os recursos necessários seriam disponibilizados. De qualquer forma, pode-se apontar esta deficiência como um problema importante de implementação e institucionalização das atividades de RSC nas empresas.

No entanto, quando existe esse orçamento, este é gerenciado, em $33,5 \%$ dos casos, pela presidência/diretoria. Novamente fica evidenciada a importância atribuída ao tema RSC. Coerente com a alocação departamental, em $15 \%$ dos casos a responsabilidade sobre o orçamento específico é uma 
atribuição do departamento de pessoas. Os demais possíveis responsáveis pelo orçamento como departamento de controladoria, marketing, relações públicas, ou ainda o responsável, o comitê ou o departamento específico pelas atividades/programas de RSC receberam entre $8,5 \%$ e $3,5 \%$ das respostas.

\subsection{Sistema de tomada de decisão relativa às atividades de RSC}

Quanto ao enquadramento das certificações reconhecidas internacionalmente, $72 \%$ das empresas pesquisadas afirmaram que possuem alguma certificação. Interessante é o fato de que estes mesmos
$72 \%$ possuem atividades/programas de RSC. Isto comprova a proposição do presente estudo de que há ligação entre o engajamento às práticas de RSC e a certificação. No grupo de empresas que não possuem certificações, $28 \%$ das empresas pesquisadas, $16 \%$ também apóiam atividades de RSC. Em termos de tipos de certificações, dos $72 \%$ que afirmaram positivamente, $53 \%$ declararam que são certificadas segundo a ISO 9001 - que assegura um padrão de qualidade -, seguida por $33 \%$ de empresas certificadas pela ISO 14001. A menos indicada, com apenas $2 \%$, foi a SA 8000 - certificação que trata de temas inerentes a RSC.

Tabela 3 - Atual sistema de tomada de decisão relativa às práticas de RSC no contexto internacional de acordo com Arthaud-Day

\begin{tabular}{|c|l|r|r|}
\hline $\begin{array}{c}\text { Abordagens do sistema de } \\
\text { tomada de decisão de RSC no } \\
\text { contexto internacional }\end{array}$ & $\begin{array}{c}\text { Caracterização do atual sistema de tomada de } \\
\text { decisão relativa às práticas de RSC no } \\
\text { contexto internacional }\end{array}$ & $\begin{array}{c}\text { Dados } \\
\text { absolutos }\end{array}$ & $\begin{array}{c}\text { Porcen- } \\
\text { tagem das } \\
\text { respostas }\end{array}$ \\
\hline \multirow{2}{*}{ Multinacional } & $\begin{array}{l}\text { A filial brasileira é a principal responsável e a } \\
\text { matriz na Alemanha colabora }\end{array}$ & 23 & 19 \\
\cline { 2 - 4 } & A filial brasileira é exclusivamente responsável & 7 & $\mathbf{3 8}$ \\
\cline { 2 - 4 } & $\begin{array}{l}\text { Filial no Brasil e matriz na Alemanha respondem } \\
\text { igualmente }\end{array}$ & 7 \\
\hline Transnacional & $\begin{array}{l}\text { A matriz na Alemanha é a principal responsável e } \\
\text { a filial no Brasil colabora }\end{array}$ & \\
\hline Internacional & $\begin{array}{l}\text { A matriz na Alemanha é exclusivamente } \\
\text { responsável }\end{array}$ & 2 \\
\hline Global & $\begin{array}{l}\text { Existe uma diretriz global acerca de RSC para } \\
\text { todas a unidades da empresa ao redor do mundo }\end{array}$ & 3 \\
\hline
\end{tabular}

Fonte: elaborada pelos autores.

A questão relativa ao sistema de tomada de decisão de RSC no contexto internacional foi respondida apenas pelas empresas que afirmaram possuir atividades/programas de RSC. Portanto, a amostra aqui compreende 60 empresas. Os dados são apresentados na tabela 3 .

O ponto de partida para caracterizar a discussão da RSC no contexto internacional, exige a retomada de um resultado apresentado na tabela 2 , quando da discussão sobre o envolvimento no planejamento e implementação da RSC nas empresas. As empresas respondentes indicaram que em $31,5 \%$ a matriz se envolve diretamente na decisão acerca das atividades/programas de RSC. Complementarmente foi investigado sobre o atual sistema de tomada de decisão relativa às atividades de RSC no contexto internacional.

$\mathrm{Na}$ opinião das empresas brasileiras com capital alemão, o sistema é do tipo multinacional (tab. 3). No levantamento surgem duas possibilidades centrais de formas de sistema de tomada de decisão nessa direção. A primeira, com $38 \%$ das respostas, aponta que a 'a filial brasileira é a principal responsável e a matriz na Alemanha colabora'. A segunda afirmação recebeu $32 \%$ das respostas e refere-se ao sistema onde 'a filial brasileira é exclusivamente responsável'. Corroborando com estas duas, pode-se incluir ainda a afirmação que recebeu $12 \%$ das respostas, na qual 'filial no Brasil e matriz na Alemanha respondem igualmente' pelas atividades/programas de RSC. No total são $82 \%$ das respostas com conotação multinacional do sistema de tomada de decisão acerca de RSC.

\section{DISCUSSÃO DOS RESULTADOS: TENDÊNCIAS DECORRENTES DA ANÁLISE DOS DADOS}

No quadro 4, fez-se um resumo que possibilita a comparação entre as proposições teóricas e os resultados empíricos. Observa-se que seis das nove proposições foram sustentadas pelo levantamento empírico. Interessante, no entanto foi a não comprovação da alocação departamental da RSC, pois 
Impactos da Adoção de Atividades de Responsabilidade Social Corporativa na Estrutura Organizacional: Estudo das Multinacionais Alemãs no Brasil

nas empresas pesquisadas observou-se ser esta uma atividade entendida como parte da gestão de pessoas e não de marketing. Isso em casos onde não havia um setor responsável pelo tema RSC.

Relativo às proposições confirmadas, destacase o fato da RSC ser relevante nas empresas pesquisadas face a posição ocupada pelos seus responsáveis. Portanto, comprova-se a afirmação de Naor (1982, p. 223), o qual indica que a gestão da RSC é uma função que deve ser subordinada ao alto escalão executivo e, portanto, com ligação direta ao top management. Nesse sentido, a coordenação de RSC pode ser enquadrada como estratégico nas empresas pesquisadas.

Corroborando a afirmação de entendimento estratégico da RSC, retomam-se os dados acerca do perfil dos responsáveis pelas atividades/programas de RSC. Estes, em sua maioria, possuem alto grau de instrução, apresentam experiência em termos de tempo de empresa e ocupam posições de direção em suas respectivas empresas. 


\begin{tabular}{|c|c|c|c|}
\hline CATEGORIAS & PROPOSIÇÕES & RESULTADOS DO LEVANTAMENTO EMPÍRICO & STATUS \\
\hline \multirow{7}{*}{$\begin{array}{l}\text { Coordenação da } \\
\text { RSC na } \\
\text { estrutura } \\
\text { organizacional }\end{array}$} & $\begin{array}{l}\text { O planejamento e implementação das atividades de RSC } \\
\text { cabe ao nível estratégico da cadeia escalar nas empresas } \\
\text { pesquisadas. }\end{array}$ & $\begin{array}{l}\text { - Das empresas pesquisadas } 83,5 \% \text { afirmaram que a presidência/diretoria se envolve no } \\
\text { planejamento e implementação das atividades/programas de RSC. } \\
\text { - Em segundo lugar - com 73,5\% das respostas - envolvem-se nesse processo os ocupantes da } \\
\text { média gerência. }\end{array}$ & Confirmada \\
\hline & $\begin{array}{l}\text { Empresas, que possuem atividades de RSC, possuem uma } \\
\text { ou mais pessoas responsáveis pelo desenvolvimento e } \\
\text { implementação destas atividades. }\end{array}$ & $\begin{array}{l}\text { - Em 38,5\% das empresas pesquisadas há uma pessoa responsável pelo tema RSC. } \\
\text { - Em 13,5\% há a existência de um departamento dedicado especificamente para coordenar as } \\
\text { atividades concernentes a RSC. }\end{array}$ & Confirmada \\
\hline & $\begin{array}{l}\text { Caso a(s) pessoa(s) designada(s) para coordenar as } \\
\text { atividades de RSC não pertencer ao alto escalão da } \\
\text { executivo, esta(s) estará diretamente subordinadas ao } \\
\text { corpo diretivo da empresa. }\end{array}$ & $\begin{array}{l}\text { - A maioria dos respondentes - mit } 71 \% \text { - indica que a pessoa responsável pelas } \\
\text { atividades/programas de RSC responde diretamente para a presidência/diretoria. Na sequência, em } \\
21 \% \text { das empresas respondentes, se reportam para a média gerência. }\end{array}$ & Confirmada \\
\hline & $\begin{array}{l}\text { O nível hierárquico do responsável pelas atividades de } \\
\text { RSC pertence ao alto escalão executivo das empresas. }\end{array}$ & $\begin{array}{l}\text { - 15\% das empresas pesquisadas, que possuem no mínimo uma pessoa responsável pelas } \\
\text { atividades/programas de RSC, apontam que esta pertence a presidência/diretoria. } \\
\text { - No entanto, } 42 \% \text { dos responsáveis pelas atividades/programas de RSC pertencem à média } \\
\text { gerência. }\end{array}$ & Parcial \\
\hline & $\begin{array}{l}\text { O responsável específico pelas atividades de RSC na } \\
\text { empresa é do sexo masculino, possui experiência de mais } \\
\text { de } 2 \text { anos na empresa, preponderantemente possui } \\
\text { formação acadêmica e ocupa uma posição de direção no } \\
\text { setor em que trabalha. }\end{array}$ & $\begin{array}{l}\text { - } 62 \% \text { dos responsáveis específicos pela RSC possuem mais do } 36 \text { anos, a maioria, } 56 \% \text {, são } \\
\text { homens e } 89 \% \text { dos respondentes tem formação acadêmica. } \\
-42 \% \text { ocupam funções de média gerência (gerentes ou coordenadores de suas áreas) e } 15 \% \text { ocupam } \\
\text { funções na presidência/diretoria. O tempo de trabalho na empresa é de mais de } 10 \text { anos em } 38 \% \text { dos } \\
\text { casos e entre } 3 \text { e } 10 \text { anos para } 35 \% \text { dos casos. }\end{array}$ & Confirmada \\
\hline & $\begin{array}{l}\text { A coordenação e gerenciamento do orçamento das } \\
\text { atividades/programas de RSC ficam a cargo do } \\
\text { departamento de marketing. }\end{array}$ & $\begin{array}{l}\text { - Para } 61,5 \% \text { dos respondentes o tema é de responsabilidade da área de gestão de pessoas. Outros } \\
\text { setores como marketing, controladoria, operações, relações públicas receberam baixas taxas de } \\
\text { respostas entre } 11,5 \% \text { e } 5 \% \text {. }\end{array}$ & Negada \\
\hline & $\begin{array}{l}\text { Existe um orçamento específico para o desenvolvimento } \\
\text { de atividades/programas de RSC pertence ao alto escalão } \\
\text { executivo. }\end{array}$ & - Verifica-se uma carência da existência deste instrumento em 45\% das empresas respondentes. & Parcial \\
\hline \multirow[t]{2}{*}{$\begin{array}{c}\text { RSC em } \\
\text { Multinacionais }\end{array}$} & $\begin{array}{l}\text { Considerando o contexto internacional o atual sistema de } \\
\text { tomada de decisão relativa às atividades de RSC nas } \\
\text { empresas pesquisadas é o multinacional. }\end{array}$ & $\begin{array}{l}\text { - No total } 82 \% \text { das empresas respondentes apontam que o sistema de tomada de decisão relativa às } \\
\text { atividades de RSC é o multinacional. } \\
\text { - Corroborando com o direcionamento multinacional as empresas pesquisadas claramente negam } \\
\text { que a matriz ou a filial devam ter obrigação exclusiva sobre as decisões acerca da RSC. }\end{array}$ & Confirmada \\
\hline & $\begin{array}{l}\text { Empresas que possuem certificação tendem a se dedicar às } \\
\text { atividades de RSC. }\end{array}$ & $\begin{array}{l}-72 \% \text { das empresas pesquisadas afirmaram que possuem alguma certificação e estes mesmos } 72 \% \\
\text { possuem atividades/programas de RSC. }\end{array}$ & Confirmada \\
\hline
\end{tabular}

Quadro 4 - Quadro comparativo entre as proposições teóricas e a comprovação empírica

Fonte: Elaborado pelos autores. 
Em termos de coordenação das atividades de RSC, observou-se o início da consolidação da gestão do tema no cotidiano das empresas pesquisadas. Para tanto, existem algumas possibilidades: um 'padrinho', pessoa que se dedica exclusivamente à gestão da RSC na empresa; um comitê incluindo diversos setores da empresa; conselhos consultivos; comissão de funcionários ou um departamento específico para gestão do da RSC. Cabe apontar o fato de que há uma contradição em termos de implementação da RSC, haja visto que não há uma determinação de um orçamento específico para RSC, o que implica em pouca autonomia acerca de sua gestão nas empresas pesquisadas. Portanto, as empresas pesquisadas encontram-se em um estágio embrionário de inserção da RSC em suas estruturas, o que corrobora as pesquisas de Khan e Atkinson (1987).

Concernente ao sistema de tomada de decisão há uma comprovação empírica da proposta por Arthaud-Day (2005, p.9), onde verificou-se que a forma multinacional da gestão de RSC é a que melhor descreve a realidade das empresas brasileiras com capital alemão. Por consequência entende-se que essas filiais brasileiras de multinacionais alemãs podem ser consideradas como 'agentes ativas' da gestão de RSC.

\section{CONSIDERAÇÕES FINAIS}

O objetivo do presente artigo foi esclarecer quais são os impactos da adoção de atividades de Responsabilidade Social Corporativa na estrutura organizacional das empresas, bem como se dá o processo de tomada de decisão no contexto internacional, em especial as empresas brasileiras com capital alemão. Especificamente, investigou-se as formas de inserção da coordenação das atividades de RSC nas empresas, a qualificação do tema em termos de nível organizacional de sua implementação e dos departamentos envolvidos, a descrição do perfil dos responsáveis, apuração da existência de orçamento específico de RSC. Por fim, procedeu-se a caracterização do sistema de tomada de decisão sobre RSC no contexto internacional e relacionou-se a adequação às certificações com ao engajamento às práticas de RSC. Esse levantamento foi realizado com 76 empresas alemãs, da indústria de transformação, que atuam no Brasil.

Observou-se que na coordenação das atividades de RSC, as empresas pesquisadas encontram-se em um estágio embrionário de inserção da RSC em suas estruturas. Destaca-se ainda, o fato da RSC ser relevante nas empresas pesquisadas face ao perfil dos responsáveis pelas atividades/programas de RSC e suas respectivas posições na estrutura organizacional.
Concernente ao sistema de tomada de decisão considera-se as filiais brasileiras de multinacionais alemãs como 'agentes ativas' da gestão de RSC nos seus contextos locais.

Complementarmente, pode-se apontar outra contribuição do presente artigo em elaborar uma tipologia das principais atividades de RSC na esfera internacional, que engloba um amplo espectro de atividades legais, econômicas, sociais, éticas e ecológicas em três diferentes níveis de atuação: 1) de longo prazo e voltado ao meio externo; 2) de médio prazo e intercalado entre o meio externo e interno; 3 ) de curto prazo e voltado ao meio interno.

As limitações do presente estudo consistem na amostra ser restrita à empresas brasileiras com capital alemão e ser circunscrita ao setor industrial. Portanto, a generalização dos dados não é possível e nem havia a intenção que o fossem. Consequentemente, como sugestão para posteriores estudos, propõe-se que outros ramos de atividades e/ou organizações com composição acionária de outros países sejam consideradas e investigadas, utilizando para isso as categorias de análise aqui propostas, ou ainda pelo aprofundamento de algumas delas com seus respectivos desdobramentos em fatores e critérios de análise descritos no quadro 3.

Apesar dessas limitações, esse artigo contribui para a discussão da complexidade da temática RSC no contexto internacional e como parte integrante da estratégia da empresa e não mais como ações pontuais e isoladas utilizadas para ancorar ações de cunho propagandista. Da mesma forma, imagina-se que a investigação sistemática da temática acerca da RSC, possibilite a construção do conhecimento da RSC à partir de um conceito estratégico, como alternativa de modelo de negócios, aplicação prática no cotidiano empresarial e suas implicações para os gestores.

\section{REFERÊNCIAS}

Arthaud-Day, M. L. (2005). Transnational corporate social responsibility. A tri-dimensional approach to international CSR research. Business Ethics Quarterly, Vol. 15 (Issue 1), 1-22.

Carroll, A. B. (1979). A three-dimensional conceptual model of corporate performance. Academy of Management Review, 4(4), 497-505.

Carroll, A. B. (1991). The pyramid of corporate social responsibility: Toward the moral management of organizational stakeholders. Business Horizons, 34(4), 39-48. 
Impactos da Adoção de Atividades de Responsabilidade Social Corporativa na Estrutura Organizacional: Estudo das Multinacionais Alemãs no Brasil

Cramer, J., Jonker, J., \& van der Heijden, A. (2004). Making sense of corporate social responsibility. Journal of Business Ethics, 55(2), 215-222.

Davis, K. (1973). The case for and against business assumption of social responsibilities. Academy of Management Journal, 16(2), 312-322.

Davis, K., \& Frederick, W. C. (1985). Business and Society: Management, Public Policy, Ethics (5th ed.). Singapore: McGraw-Hill.

Eilbirt, H., \& Parket, I. R. (1973). The Corporate Responsibility Officer: a new position on the organization chart. Business Horizons, 16(1), 4551 .

Enderle, G., \& Tavis, L. A. (1998). A balanced concept of the firm and the measurement of its long-term planning and performance. Journal of Business Ethics, 17(11), 1129-1144.

Eu-Kommission. (2001). Grünbuch-Europäische Rahmenbedingungen für die soziale Verantwortung der Unternehmen. KOM (2001), 366.

Freeman, R. E. (1984). Strategic Management: A Stakeholder Approach. Londres: Pitman Publishing.

Friedman, M. (1988). Capitalismo e liberdade. Editora Artenova.

Garriga, E., \& Melé, D. (2004). Corporate social responsibility theories: Mapping the territory. Journal of Business Ethics, 53(1-2), 51-71.

Gazdar, K. (2006). Das Good-Company-Ranking im internationalen Vergleich. In: Gazdar, Kaevan, Habisch, André, Kirchhoff, Klaus Reiner, Vaseghi, Sam. Erfolgsfaktor Verantwortung - Corporate Social Responsibility professionell managen, Springer, 51-60.

Gil, A. C. (1996). Métodos e técnicas de pesquisa social (5th ed.). São Paulo: Atlas.

Habisch, A. (2006). Corporate Citizenship: Gesellschaftliches Engagement von Unternehmen in Deutschland. Berlin: Springer-Verlag.

Hansen, U., \& Schrader, U. (2005). Corporate social responsibility als aktuelles Thema der Betriebswirtschaftslehre.

BETRIEBSWIRTSCHAFT-STUTTGART-, 65(4), 373-395.
Holme, R., \& Watts, P. (2000). Corporate Social Responsibility: Making Good Business Sense. World Business Council for Sustainable Development.

Homann, K. (2004). Gesellschaftliche Verantwortung als Business Case. In U. Schneider \& P. Steiner, Betriebswirtschaftslehre und gesellschaftliche Verantwortung (pp. 1-16). Wiesbaden: Gabler.

Hopkins, M. (1997). Defining indicators to assess socially responsible enterprises. Futures, 29(7), $581-603$.

Khan, A. F., \& Atkinson, A. (1987). Managerial attitudes to social responsibility: A comparative study in India and Britain. Journal of Business Ethics, 6(6), 419-432.

Loew, T., Ankele, K., Braun, S., \& Clausen, J. (2004). Bedeutung der internationalen CSR-Diskussion für Nachhaltigkeit und die sich daraus ergebenden Anforderungen an Unternehmen mit Fokus Berichterstattung: Endbericht. Münster, Berlin: Future e.V.

Matten, D., \& Crane, A. (2005). Corporate citizenship: Toward an extended theoretical conceptualization. Academy of Management Review, 30(1), 166-179.

Matten, D., Crane, A., \& Chapple, W. (2003). Behind the mask: Revealing the true face of corporate citizenship. Journal of Business Ethics, 45(1-2), 109-120.

Naor, J. (1982). A new approach to multinational social responsibility. Journal of Business Ethics, 1(3), 219-225.

Orpen, C. (1987). The attitudes of United States and South African managers to corporate social responsibility. Journal of Business Ethics, 6(2), 8996.

Ostlund, L. E. (1977). Attitudes of Managers Toward Corporate Social Responsibility. California Management Review, 19(4), 35-49.

Pereira, W. A., \& Campos Filho, L. A. N. (2007). Investigação sobre as semelhanças entre os modelos conceituais da RSC. Revista de Gestão Social E Ambiental, 1(1).

Pinkston, T. S., \& Carroll, A. B. (1994). Corporate citizenship perspectives and foreign direct investment in the US. Journal of Business Ethics, 13(3), 157-169. 
Impactos da Adoção de Atividades de Responsabilidade Social Corporativa na Estrutura Organizacional: Estudo das Multinacionais Alemãs no Brasil

Porter, M. E., \& Kramer, M. R. (2002). The competitive advantage of corporate philanthropy. Harvard Business Review, 80(12), 56-68.

Preston, L. E., \& Post, J. E. (1981). Private management and public policy. California Management Review, 56-62.

Quazi, A., \& O’Brien, D. (2000). An Empirical Test of a Cross-national Model of Corporate Social Responsibility. Journal of Business Ethics, 25(1), 33-51.

RNE, R. F. N. E. (2006). Unternehmerische Verantwortung in einer globalisierten Welt-Ein deutsches Profil der Corporate Social Responsibility. Empfehlungen Des Rates Für Nachhaltige Entwicklung. Texte, (17).

Schwartz, M. S., \& Carroll, A. B. (2003). Corporate social responsibility: A three-domain approach. Business Ethics Quarterly, 503-530.

Suchanek, A. (2003). Ökonomische Unternehmensethik: Diskussionsbeiträge der Katholischen Universität Eichstätt (166th ed.). Kath. Univ. Eichstätt, Wirtschaftswiss. Fak.

United Nations. (1999). Global Compact 1999. Retrieved from https://www.unglobalcompact.org/

Waddock, S. (2004). Parallel universes: Companies, academics, and the progress of corporate citizenship. Business and Society Review, 109(1), 5-42.

Wartick, S. L., \& Cochran, P. L. (1985). The Evolution of the Corporate Social Performance Model. Academy of Management Review, 10(4), 758-769. http://doi.org/10.5465/AMR.1985.4279099

Welzel, E. (2009). Tipologia das atividades de responsabilidade social corporativa na esfera internacional: (in)dependência do contexto cultural? (pp. 24-27). Presented at the SIMPOI, São Paulo.

Wood, D. J. (1991). Corporate social performance revisited. Academy of Management Review, 16(4), 691-718.

Zenisek, T. S. (1979). Corporate Social Responsibility. A conceptualization on organizational literature. Academy of Management Review 4/3:359-368. 